\title{
Capabilities, Human Flourishing and the Health Gap
}

\author{
Amartya Sen Lecture HDCA Conference
}

Tokyo 2016

Amartya Sen's insights have been important to my work in at least four ways: providing intellectual justification for my empirical findings that health can be an "outcome" of social and economic processes; providing insight into the debate on relative or absolute inequality; emphasising the central place of freedoms or agency in human well-being; and alerting me to the importance of the question of "inequality of what". This last is shameful to admit for someone, me, who had been pursuing research on inequalities in health for two decades before I met Sen in person and in his writings. Could I really be obsessed with health inequalities without recognising that there was more than one way to think about inequality?

In this Amartya Sen lecture, I will start by sketching briefly how these seminal ideas of Sen influence what I do. More accurately, I should say how Sen's ideas influence how I think about what I do. For, as just stated, I had been doing it for some time before I encountered Sen's fundamental contributions - I am a doctor and medical scientist, after all. In particular, my research on health inequalities has focussed on the social gradient in health, its generalisability, how to understand its causes and what to do about it. I have pursued this research since 1976 when I began work on the first Whitehall study(1), and to think about health inequalities more generally (2). Although I had not used the term, "social determinants of health" until later(3), my research on health inequalities fitted that description, along with the research on health of migrants. $(4,5)$

I will then illustrate the approach in more detail, drawing on my book, The Health Gap. (6)

\section{Social determinants of health, inequalities in health and Amartya Sen}

\section{Causal arrows}

In 1978 I published my initial paper from the Whitehall Study of British Civil Servants(1). It was my first clear demonstration of the social gradient in health. Men were classified by their grade of employment and deaths tracked over time. There was an intimate relation between employment status and risk of death: the lower the grade of employment the higher the mortality rate. This social gradient in health has exercised me ever since - in research, to understand the causes of the social gradient; and in policy, to use evidence to take action on the social determinants of health in order to improve population health and to achieve a fairer distribution of health. In particular, the challenge was to recognise not only that poverty and ill-health are highly correlated, they are, but that the social gradient applies to people who are not poor. People in the middle of the social hierarchy have worse health than those at the top, but better health than those below them. It is easy to think of the various ways poverty can cause ill-health; less easy to think why rung on the social ladder is so closely related to health among people, none of whom is poor.

All of this research and policy is based on the overarching view that the causal direction is from social circumstances to health. Such a view is, of course, not the starting assumption of most economists who teach their students that the causal direction is from health to wealth or income. I spent a great deal of space and time discussing this counter view in my book, Status Syndrome(7), and elsewhere (8). 
In my experience, if your starting assumption is that the causal arrow usually goes from health to wealth that is what you find in your studies. If your starting assumption is that social conditions are determinants of health - here I share this with health researchers from Hippocrates through Ramazzini, Virchow, Durkheim and William Farr to those in modern public health - then that is what you find in your studies. It is a frustrating clash of views because data analyses seem not to settle the problem.

Amartya Sen, unusually among economists, but not uniquely, was entirely sympathetic to my view that the social gradient in health was caused by differential exposure to social circumstances through the life course. Indeed, he invited me to various discussions to develop this view.

This debate also applies to inequalities between countries. The Commission on Macroeconomics and Health, for example, urged control of major killing diseases in order to achieve economic growth (9). From my days as an ignorant medical student, I had been speculating that the health of a society was a reflection of how well a society met the needs of its citizens. It was a revelation to come across Amartya Sen expressing this view.(10) Certainly, my motivation to study medicine was not that if we cured people they might get rich. Nor was my transition to public health because I thought controlling disease would help societies get richer. No, my view was that we should be improving society, socially and economically, to get better health; not the other way round. Dickensian conditions caused ill-health; it was not that ill-health caused Dickensian conditions of living and working. Amartya Sen, of course, convinced me that the causal direction could go both ways. That said, he became a member of the Commission on Social Determinants of Health, which I chaired.(11) I will say more of that in what follows. Before I do, though, Robert Fogel's views are interesting. He thought that improved nutrition led to economic growth, largely because without calories people could not work (12). This could be taken as evidence by both sides of the argument. In my view, nutrition is one of the mechanisms by which the social determinants of health operate - here I am consistent with McKeown(13). Alternatively, if the way nutrition contributed to economic growth were through lowered susceptibility to infectious disease, the arrow could be assumed to go the other way. The current sobering observation, though, relates to the Preston Curve (see below): above a national income of about $\$ 13,000$ per person, adjusting for purchasing power, there is little relation between national income and life expectancy. The relation doesn't go either way, in these richer countries. Or, to put in my terms, to improve health we need to improve society, not only increase national income.

\section{Relative or absolute inequality}

I mentioned Dickens above. Tales of women dying in childbirth, children dying in squalor, young adults with tuberculosis; starvation and unsanitary living conditions, debtors' prisons and dark satanic mills - there is no difficulty understanding how poverty of material conditions can lead to illhealth and premature death. But the gradient is different. Why, in modern Britain, should civil servants in the middle of the occupational hierarchy have higher death rates than those above them, but lower death rates than those below them? It is difficult to think of being in the middle of the gradient as being somewhat deprived, materially, in ways that damage health. These civil servants all have housing with plumbing and heating, stable jobs in decent offices, and money enough to put food on the table, yet there is a social gradient in health.

And not just in civil servants. Figure 1 shows the social gradient in health in the population of England. The top graph is life expectancy, the bottom disability-free life expectancy. Each dot represents a neighbourhood classified on an index of multiple deprivation. The less deprived the neighbourhood, the greater the life expectancy and disability-free life expectancy. The gradient runs 
all the way from top to bottom. Health improved in general over a decade, but the slope of the gradient did not change.

\section{Life expectancy and disability-free life expectancy (DFLE) at birth, males by neighborhood deprivation, England, 1999-2003 and 2009-2013}



At the bottom of the hierarchy, even in a rich country such as the UK in the first decades of the $21^{\text {st }}$ century, material deprivation can damage health. Resort to food banks or choosing between heating your dwelling or eating can certainly be bad for health. But people in the middle can heat and eat; why is their health worse than those at the top? This has to relate, surely, to relative inequalities. I seem to be arguing then that absolute inequalities are important when it comes to poverty of material conditions, relative when people are above that threshold of absolute deprivation.

Then I read in Amartya Sen's Inequality Reexamined(14):

"Relative inequality in the space of incomes can yield absolute deprivation in the space of capabilities."

My reformulation of this concise statement: it is not so much what you have, but what you can do with what you have that is important for health. In a low income country, low income matters because of lack of basic necessities for health and life. In a high income country, the poor are fantastically rich by global standards, adjusting for purchasing power. But relatively low income matters in so far as it interferes with capabilities - all the things that are necessary for good health, even after the basic needs for food, shelter and sanitation have been met. One of those central capabilities is having control over your life, and that led me to: 


\section{Freedoms and agency}

Here, too, I felt like Molière's Bourgeois Gentleman who discovered that he had been talking prose for decades. I had been emphasising empirical research showing the importance of how much control one had to risk of getting heart disease or mental illness when I "discovered" Sen. Or, more accurately, he detected me.

One of the puzzles about the social gradient in heart disease was that it contradicted conventional wisdom about stress and the heart. "Everyone knew" that it was more stressful to be in a high status job and such executive stress was responsible for heart attacks in high status men. Except that it wasn't true. As the Whitehall studies showed, and numerous studies have confirmed, the lower the employment level the higher the risk of heart disease and a range of other diseases. The solution to this conundrum came in the form of a model of stress at work that said it was not just demand that was important but how much control one had over the work.(15) In the Whitehall II study of civil servants we showed that low control at work predicted heart disease incidence and, statistically, contributed to the social gradient in heart disease.(7)

Perhaps it is something of a stretch to go from low control at work predicting heart disease in British civil servants to a general theory of empowerment as underlying global health inequalities, but the authority of Sen helped. His Development as Freedom put agency in central place(16). Similarly, Nicholas Stern, former chief economist at the World Bank, emphasised empowerment.(17) Putting these together I suggested that economic development and empowerment was a way of linking health inequalities within and between countries at different levels of income.(18)

\section{Inequality of what?}

I have never heard anyone who subscribes to democracy, politician or academic, say that equality of opportunity is a bad thing. The question is whether the conversation should stop there. I have two comments. First, as a doctor I am interested not only in opportunities but in outcomes - health is an outcome. If genuine equality of opportunity led to inequality in health, it would still be problematic. For example, tossing a coin to decide who stays on in high school and who starts work in a coal mine, may be genuine equality of opportunity but the health consequences of this "equality" will be dramatically different. It is precisely those concerns with health outcomes that lead us to want every child to go to high school, and to applaud a mandatory leaving age for school.

A second serious concern is that what passes for equality of opportunity is anything but. We see this by starting at the end of a process, unequal health; working back we may well find that equality of opportunity is a chimera. For example, the higher the income of parents the greater the life chances of their children, which, in turn, lead to inequalities in health. In certain quarters such focus on outcomes is dammed as consequentialist. Sen's robust defence of examining capabilities and functionings gives succour to those of us who recognise the central place of health as outcome.

Philosopher Michael Sandell suggests three approaches to social justice: maximising welfare, promoting freedom, and rewarding virtue. Influenced by Sen's formulation of freedoms, and my own work on control or empowerment, I give great emphasis to freedoms. But I emphasise that is not a libertarian notion of freedoms but we need social action to create the conditions, to quote Sen, for people to lead lives they have reason to value. 


\section{The Health Gap. The Challenge of an Unequal World}

The book I published in 2015 with the above title weaves together three strands of work: a conceptual approach that incorporates what I have just sketched above; an account of empirical work setting out the evidence on social determinants of health equity, explaining the gradient in particular; and a call to action to create fairer societies, based on the best evidence on what can be done.

\section{Social Justice and Health - creating fairer societies}

'Social injustice is killing on a grand scale' is my message to policy makers. So much so that, as chair, I put it on the cover of the report of the WHO Commission on Social Determinants of Health, Closing the Gap in a Generation. (11) Our view was that inequalities in health between social groups that are judged to be avoidable by reasonable means, and are not avoided, are unfair - hence health inequities. Our conceptual framework is shown in Figure 1. Health, and the unfair distribution of health, are the outcomes.

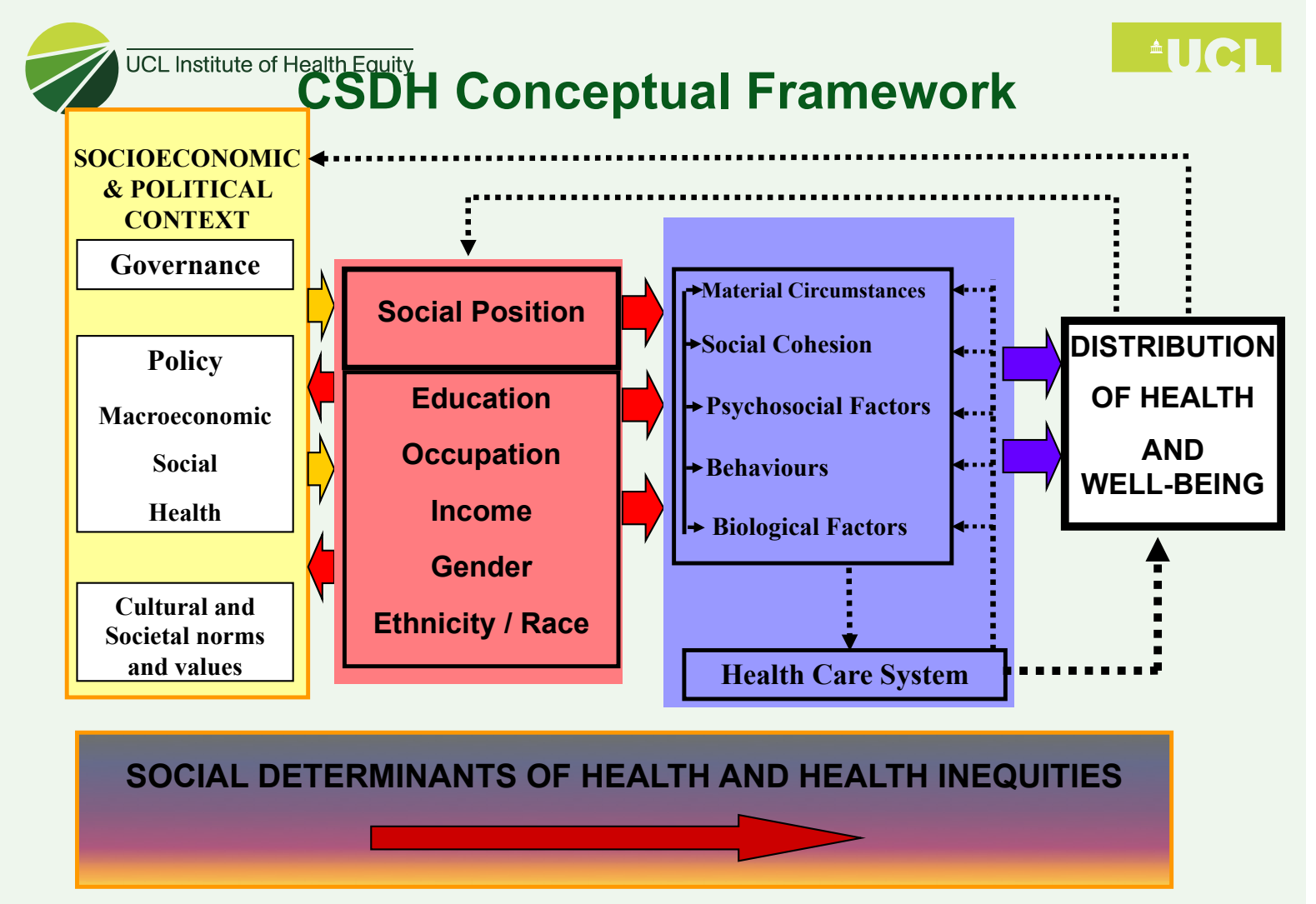

Source: CSDH Final Report, WHO 2008

The starting point for most people when they contemplate inequities in health is a focus on inequities in health care. There are undoubted inequities in health care, and these must be addressed through universal health coverage, but the social determinants of health framework makes clear that we have to address the causes of ill-health. The message with which I begin The Health Gap: what good does it do to treat people and send them back to the conditions that made them sick. 
Variations in the conditions that make people sick are in grim display in the US city of Baltimore Maryland. Such conditions do not lead only to ill-health. In early 2015 Baltimore erupted. Civil unrest broke out. The precipitant of the riots was the killing of a black man in police custody. Or should I say one more killing of a black man by the police. But the underlying cause of the riot was inequality of social and economic conditions.

I said Baltimore erupted, but it was one part of Baltimore, the poor inner city, that erupted. I had been studying health inequalities in Baltimore before there was civil unrest. In the poor part, where the riots broke out, life expectancy for men was 63 years. In the richest part it was 83 years. A twenty year difference in life expectancy in one city. If you live in the rich part of Baltimore and want to see what it is like to live in a place with male life expectancy 63 , you could fly to Ethiopia. Easier is to travel a short way across town. Life expectancy for men in the poorest part of Baltimore is the same as in Ethiopia, two years shorter than the Indian average.

A link between riots and ill-health is not unique to Baltimore. In summer 2011 in London, riots broke out. They started in Tottenham in North London. Eerily, the precipitant was the killing of a black man by the police. As with Baltimore, the underlying cause was inequality. I had been pointing to figures on health differences in London. For men, life expectancy in the most down at heel part of Tottenham was 17 years shorter than in the ritziest part of Kensington and Chelsea. No surprise that the rioting should have broken out in Tottenham not in Kensington and Chelsea.

Why this link between ill-health and crime? I don't think that ill-health causes civil unrest or that riots cause ill-health - except in the obvious way that people can be injured. No, I think the social conditions in which people are born, grow, live, work and age are strongly determinative both of risk of ill-health and of likelihood of engaging in civil disorder. The Guardian newspaper reported that of 1000 rioters going through the magistrate's court fewer than $9 \%$ had a job or were in training; $91 \%$ of these young people were what is known in the jargon as NEET - not in employment education or training. Nationally, at that time, the NEET figure was about $10 \%$. A stark contrast: $91 \%$ of rioters not in employment education or training versus $10 \%$ among non-rioters. There were no trainee lawyers, accountants and doctors among the rioters, or plumbers, drivers and shop assistants, but people who had little to lose and uncertain futures.

I have put understanding the gradient in health at the core of my activities, but one way of searching for explanations is by looking at the extremes. To do that, let's return to Baltimore, where men in the worst off part, Upton Druid, have life expectancy of 63; men in the best off, Roland Park, have life expectancy of 83 . The comparisons of the two are stark.

In 2010, median family income was $\$ 17,000$ in Upton Druid; $\$ 90,000$ in Roland Park. In Upton Druid, half are single parent families; 7\% in Roland Park. In Upton Druid, 90\% of the young people don't go to college; in Roland Park, 75\% complete college. In Upton Druid, one third of people aged 10-17 are arrested each year for a juvenile disorder. One third each year means that the chance of getting to age 17 without a criminal record is quite slim. In Roland Park, it was not one third each year but one in fifty.

In theory, the slate is wiped clean at 18 , no criminal record. In theory. You apply for a job and you are asked have you ever been in trouble with the police. I suppose you could lie, but that is hardly a good qualification for getting a job. Or you could tell the truth which, given your record, is not a good qualification for getting a job. 
Then there is the American disease: guns. In Upton Druid, over a 4 year period there were 100 nonfatal shootings per 10,000 residents and 40 homicides. In Roland Park, there were no non-fatal shootings and 4 homicides, one tenth of the rate in Upton Druid.

What these comparisons make clear is that we need to look at the whole of life from early childhood to older age and the life chances that differ so dramatically between areas even within one city. And we need to look at the differences in life chances precisely because the health outcomes are so different.

It is also worth adding that, in some quarters, the poor are blamed for their own ill-health. The argument seems to be that knowledge of the harms of smoking, poor diet, obesity and alcohol misuse are widely available. If the poor persist in these behaviours, they have no one to blame but themselves. I invite someone who holds this view to go to Upton Druid, and tell a youth who has just been released from police custody, and as a result can't get a job, that he really shouldn't smoke as it might cause heart disease or cancer when he's in his fifties. To put it delicately, he would be given short shrift. We need to address the social determinants of behaviours and of ill-health.

\section{Evidence-based policy on social determinants of health and heath equity}

The WHO Commission on Social Determinants of Health (CSDH) was global in scope. We said that it was vitally important for countries, and perhaps cities, to adapt the recommendations of the CSDH into evidence based policies adapted to national and local contexts. The British government invited me to conduct such a review for one country, England. The Marmot Review, so called, was published as Fair Society Healthy Lives.(19) We had six domains of recommendations, the evidence for each of which is dealt with in The Health Gap:

- Give every child the best start in life

- Education and life-long learning

- Employment and working conditions

- Ensure everyone has at least the minimum income necessary for a healthy life

- Healthy and sustainable places in which to live and work

- Taking a social determinants approach to prevention

I will illustrate some key points in what follows. Central to my agenda is that the "Marmot Six" provide explanations and a basis for action to reduce the social gradient in health as well as to interrupt the link between poverty and ill health. In each of these six domains we see social gradients in determinants of health.

\section{Give every child the best start in life}

What happens to children in the early years has a profound effect on their life chances and hence their health as adults. At the heart of it is empowerment, developing the capacities for, and having the conditions that allow, enjoyment of basic freedoms that give life meaning. Early child experiences have a determining influence on that development. Early child development is influenced in part by quality of parenting or caring from others; which in turn are influenced by the circumstances in which parenting takes place.

The higher the income of parents, and the more education, the better do their children score on measures of early child development. We have been monitoring early child development in Britain and find that the more economically deprived a neighbourhood is, the lower the proportion of 
children, at age 5, that have a good level of development: cognitive, linguistic, social, emotional and behavioural. There is a clear relationship: more deprivation means worse early child development. But that's not all there is. Pick any given level of deprivation, and you will see that some local areas are doing better than others - they have a higher proportion of children ready for school.

These findings serve as a political litmus test. People on the right politically blame poor parenting; those on the left say it is poverty and deprivation. I say they're both correct. The social conditions in which parents are trying to raise their children affect their ability to be "good" parents.

To test out the contribution of parenting activities to the social gradient in child development, a group of us at University College London analysed data from the Millennium Birth Cohort Study, a national study in England. Looking at fifths of household income, we saw a clear gradient: the lower the income the worse the early child development. We then asked mothers of children aged three: was it important to talk to a child? About 20 percent of mothers denied that talking to a child was important. And this followed the social gradient - the lower the income the more likely were mothers to deny the importance of talking to a child. We asked: is it important to cuddle a child? Is there anything in the world more fulfilling than cuddling a child? About $20 \%$ of mothers denied that it was important to cuddle a child aged 3. Talking, cuddling, playing, reading singing - all those "normal" parenting activities - showed a social gradient: the lower the income the less frequent these activities.

Our analyses suggested that about a third of the social gradient in linguistic development and about half of the differences in social and emotional development could be attributed to differences in parenting.(20)

Think about these findings in relation to a family living in material deprivation. A well meaning child expert says: you should read bed-time stories to your children. The response might be: I would if I were sure I had a bed, let alone a book. Remember the gradient, though. Families in the middle of the income range were, to be sure, engaging more with their children than the poor; but were engaging less than those with more income.

Finding that good child development is less common in deprived areas suggests one strategy for improving early child development: reduce deprivation and, more generally, inequality. Finding that for a given level of deprivation some areas are doing better than others suggests a complementary strategy: support parents and families. There is evidence of benefit from both strategies.

One measure of deprivation and inequality is child poverty. We can compare countries by looking at the proportion of children living in families whose income is less than $50 \%$ of the median. Of course, no society takes poverty as a given. The finance minister can use the tax system to redistribute income. He (ministers of finance are rarely she) can also apportion benefits to the needy: so-called social transfers. Some countries use these mechanisms more than others and thus policy can have marked differences in its effect on child poverty. I was writing about this for an American publication and wanted to compare the US with another country. I thought if I took Sweden as my comparator, Americans would say Sweden?! A Marxist-Leninist hell hole. So I chose Australia. To some Americans, Australia sounds a bit like Texas. Or perhaps California.

In the US before actions by the minister of finance, 25 percent of children were in poverty, defined as households at less than 50 percent of the median national income. In Australia, 28 percent were in poverty. In the US, after taxes and transfers, poverty levels were reduced just a little, from 25 to 23 percent. But in Australia poverty levels dropped from 28 percent to 11 percent.

The editor of the US publication for which I was writing said: "I think we should take this section out. 
I think you are talking about redistribution and there is no appetite for that in the US."

I replied: "I am talking about redistribution. If there is no appetite for it in America, that is precisely why we should leave it in."

The editor said: "OK. But I don't get it. I know what taxes are. But what are transfers?"

"They're benefits paid."

"Let me see if I understand this" said the editor. "You are saying that in Australia middle income earners, let's say, pay taxes and that money provides money and services to poorer people"

\author{
"Absolutely" \\ "Really," he said, "some countries actually do that!"
}

Australia uses taxes and transfers to reduce inequality and child poverty to a far greater extent than the US does. Although, many countries have a fairer distribution of income and lower child poverty than Australia. In Report Card 13, the latest report on inequalities in child well-being from UNICEF, Australia ranks behind 15 other countries on child poverty. These 15 countries include Korea and Slovenia as well as the usual suspects: the Nordic countries, Switzerland, Netherlands, Germany and France.

The complementary strategy is supporting families and children, whatever the level of deprivation. Not long ago, I got on my bicycle and peddled off to Hackney, traditionally a very deprived area in East London. Now, it shows the economic and social gradient in pure culture, ranging from pockets of deprivation all the way to rapidly gentrifying areas where house prices are beyond the reach of mere university graduates. I showed graphs of the link between deprivation and both poor early child development and poor school performance. The head of education said that these figures don't apply in Hackney. She said: "We tell ourselves everyday: poverty is not destiny! We have broken the link between deprivation and poor early child development."

Indeed they have. One way of looking at family poverty in Britain is to use eligibility for free school meals as a marker for poverty. These children, eligible for free school meals, score worse than the average on various measures of development at the end of the first, reception, year of school. In Hackney, though, the gap is tiny. The difference in early child development between the deprived children and the average is hardly discernible. In more affluent parts of England, however, the gap is huge. Poverty is not destiny. Having quality pre-school services and educationalists who are committed to bringing the performance level of deprived children up to that of the average makes a major difference). My guess is that in more affluent parts of the country, where deprived children are more of a rarity, they are not geared up to deal with the problem. Poverty is not destiny. (see Institute of Health Equity Monitoring Report - accessed 5 Dec 2016 https://www.instituteofhealthequity.org/projects/marmot-indicators-2015)

There is much to say on education, the second domain of the Marmot Review. Here, I will confine myself to the observation that first, early child development is a potent predictor of subsequent performance in the education system. Children who score higher on a measures of early child development, readiness for school, fare better during their school careers. Further, OECD showed that PISA scores (Program on International Student Assessment) on maths and science at aged 15 are consistently higher in children who attended pre-school. 
Second, the same sets of drivers of good early child development are also drivers of good school performance: family effects, general socioeconomic forces, and quality of schools and teachers.

Education, of course, is a vital step on the path of achieving both the capacity to control your life, and the conditions of income, employment and living conditions that make such control more possible.

\section{Employment and Working conditions}

Empowerment implies having developed appropriate personal resources and enjoying the conditions that enable control over one's life. Good early child development and education are key to the first, personal resources. Good employment and working conditions are among the determinants of the second, conditions that allow personal control to be exercised.

In the report of the CSDH, we said that inequities in power, money and resources drive inequities in the conditions of daily life; which, in turn, drive health inequities. Work and employment is one area where inequities in power, money and resources all play out.

The ultimate work-related disempowerment is unemployment. Of course, when there is an economic downturn, unemployment is not randomly distributed. The more years of education the lower the likelihood of unemployment, of young people in particular. It is a paradigmatic example of the intersection of effects from early life and current conditions in influencing empowerment. Nor does unemployment strike randomly among populations. Unemployment among 15 - to 24-year-olds in Spain was as high as 58 per cent. It is now "only" 43\%. In Greece the figures are even higher, 50 per cent of young people unemployed; in Italy 37 per cent. Society's implied promise to these young people has been broken - grow up, go to school, study, prepare, and then it will be your turn to embark into the world of work, earn your living and do what every generation has done before.

Globally, the great recession has been disastrous for employment. The International Labour Organisation (ILO) estimates that in 2013 there were over 200 million people unemployed in the world. An economic crisis begun in Wall Street and the City of London is depriving young people of work in North Africa and the Middle East, parts of Latin America and the Caribbean, as well as Southern Europe.

Elsewhere, the real unemployment is hidden. In a country like India, more than 80 per cent of working people are in the 'informal' sector. If the economy turns down, they do not go and register with their unemployment office - there is no such thing. They pick up rubbish, clean latrines, take whatever demeaning work is available. The alternative to work is not unemployment benefits. It is starvation if they do not do whatever it takes to earn a tiny amount of money.

Not usually given to hyperbole, I have described this youth unemployment as a public health time bomb. Unemployment is bad for health and it blights lives. Young people who leave school for the scrapheap are in danger of never getting the habit of work - potentially, they face a lifetime on the margin.

Unemployment is particularly bad for mental health. Some of our politicians claim that unemployment is a lifestyle choice. If so, it is an odd one as it puts people at increased risk of depression and suicide. 
David Stuckler from Oxford University looked at figures for Europe and showed that a rise in a country's unemployment rate was correlated with a rise in that country's suicide rate. A dramatic finding, though, was that the size of the effect varied according to how generous a country was in its spending on social protection - which included unemployment benefits, active labour market programmes, family support and health care.(21)

The analysis was a bit complex but the conclusion was straightforward: unemployment damages mental health so severely that it can even lead to suicide, but government policies can make a difference.

Work, too, can be disempowering. Under "freedoms and agency" above, I described findings from the Whitehall II study of British civil servants that low control was related in a graded way to position in the employment hierarchy: the lower the position the less control entailed in the job. This systematic link accounts in part for progressively higher rates of heart disease and mental illness the lower the position in the hierarchy.

There is a large body of research that points to the pathogenic effects of psychosocial work characteristics: high demand and low control, imbalance between effort and rewards, organisational injustice, shift work, job insecurity. Each of these has been shown to be linked with increased risk of ill-health. Each of these tends to follow the social gradient: progressively worse the lower the social position.

\section{Inequities in money}

I endorsed Amartya Sen's formulation that relative inequalities in income can yield absolute inequalities in capabilities. An important part of the evidence base on health inequalities is that there is more to life than money: early child development, education, living and working conditions are all important. But money will be at the back of at least some of these, particularly at lower levels of income. I have, for example, made clear that child poverty is a potent driver of early child development. Policies to reduce child poverty, ceteris paribus, are likely to improve early child development and have a long term favourable impact on health equity.

One way to reduce poverty should be though work. But inequities in money, alongside inequities in power, play out in the work place. In the UK, the Joseph Rowntree Foundation monitors in-work poverty - a household below the minimum income threshold where at least one adult is working. (http://www.jrf.org.uk/data/work-poverty-levels accessed 6Nov 2016) In work poverty has been rising for the last decade - it now exceeds poverty in households where adults are retired or otherwise without work.

In the US, as recovery from the global financial crisis proceeded, for every dollar of economic growth $92 \mathrm{c}$ went to the top $1 \%$.

Work, then, should be, but is no longer the way out of poverty. There has been a subliminal message, sometimes more overt, on both sides of the Atlantic that people who are poor are workshy and hence have themselves to blame. The evidence just cited suggests not that people are poor because they are somehow feckless, but because they are lowly paid.

Part of the narrative about the work-shy is that we should spend less on benefits, on welfare, and hence encourage people back to work. I am in little doubt that work is a better option than subsisting on benefits. But when work is not an option, benefits are important. I reported Stuckler's 
work showing that the more active a country is with its active labour market programmes, including unemployment benefits, the weaker the link between unemployment rates and suicide.

More generally, the more generous a country is in its social spending the better the health and the narrower the health inequalities. This relationship is shown for European countries in Figure 3. The odds of poor health for women with primary education, compared to women with tertiary, get progressively smaller the more generous the country social expenditure.(22)

\section{Shocking news: Welfare spending improves health and reduces inequality}

Relative inequalities in health, primary vs. tertiary (women)

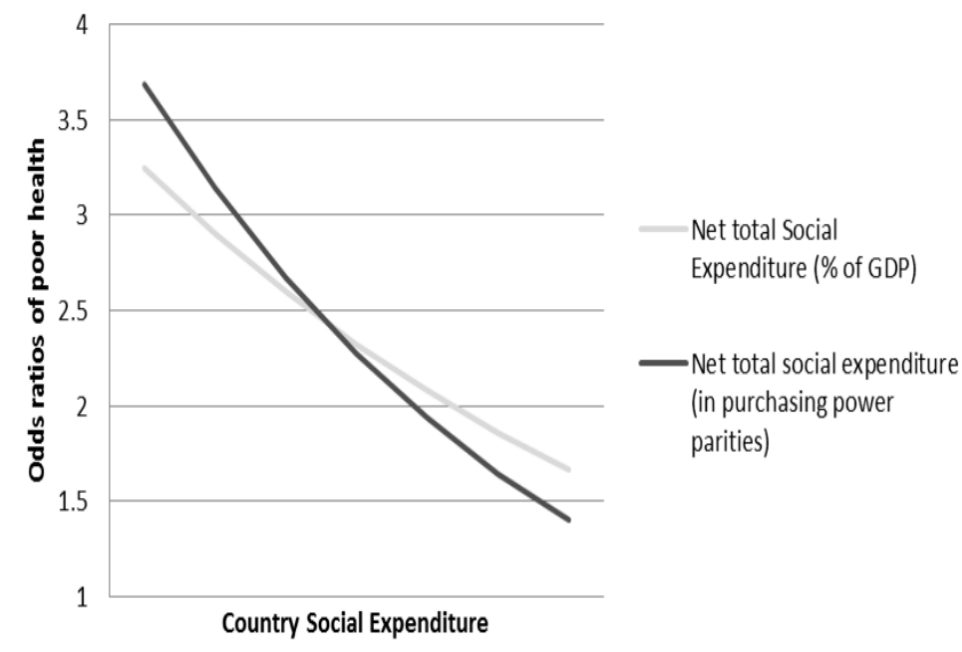

Source: Lundberg et al 2012

\section{We have lots of evidence but can we really make a difference to health equity?}

There are three answers to this question - all positive. First, one way of posing the question is to reflect that all societies have socioeconomic inequalities. If these give rise to health inequalities, then is it not inevitable that there should be a social gradient in health? Indeed, but the slope of the gradient varies. Figure 4 (reproduced in The Health Gap) shows life expectancy at 50 by level of education for fifteen European countries. As is commonly the case, inequalities in health are smaller in women than in men. Focussing on the men, the gap in life expectancy between those with only primary education and those with tertiary varies widely across countries: small in Sweden, wide in the former communist countries of Central and Eastern Europe. We do not have to accept a steep social gradient as a given. It can be shallow as in Sweden, Italy, Norway and Malta.

The second answer to the question of whether we can make a difference is that the magnitude of the gradient varies over time. In Brazil, for example, in the 1970s there was a steep social gradient in stunting - slow growth of children in the first year of life. (23) Over the next three decades, the 
gradient became progressively flatter to the point of being barely detectable - a striking social advance.

Third, there have been major reductions in health inequalities between countries. Countries such as Peru, Colombia and Brazil, which in the 1950s had male life expectancy in the 50s now have male life expectancy hovering around the 70s; for women it is longer.

(b) Life expectancy at age 50

Men

Life expectancy at 50 (years)

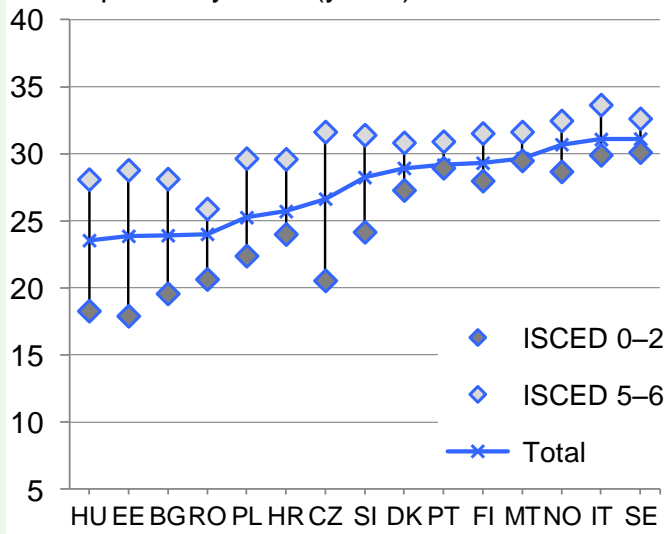

Women

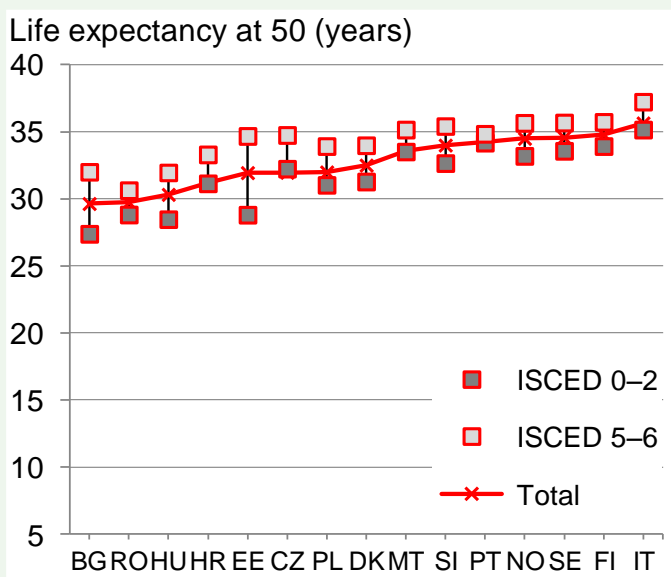

Countries are ranked by life expectancy at the specified age of the sex-specific total population. ISCED 0-2: pre-primary, primary and lower secondary education.

ISCED 4-6: tertiary education.

Source: data from Eurostat 2012

These three answers to the question of whether we can reduce health inequalities and make advances towards health equity are what I describe as my evidence-based optimism. Armed with the evidence and a commitment to social justice and creating the conditions for people to have control over their lives we can make progress towards health equity.

1. Marmot MG, Rose G, Shipley M, Hamilton PJS. Employment grade and coronary heart disease in British civil servants. Journal of Epidemiology and Community Health. 1978;32:244-9.

2. Marmot MG, Adelstein AM, Robinson N, Rose $\mathrm{G}$. The changing social class distribution of heart disease. British Medical Journal. 1978;2:1109-12.

3. Marmot M, Siegrist J, Theorell T, Feeney A. Health and the psychosocial environment at work. In: Marmot M, Wilkinson RG, editors. Social Determinants of Health. New York: Oxford University Press; 1999. p. 105-31. 
4. Marmot MG, Syme SL. Acculturation and coronary heart disease in Japanese Americans. American Journal of Epidemiology. 1976;104:225-47.

5. Marmot MG, Adelstein AM, Bulusu L. Lessons from the study of immigrant mortality. Lancet. 1984;1:1455-8.

6. $\quad$ M M. The Health Gap. London: Bloomsbury; 2015.

7. Marmot M. Status syndrome: How your social standing directly affects your health and life expectancy. London: Bloomsbury Publishing Plc; 2004.

8. Marmot M. Fair Society Healthy Lives. In: Eyal N HS, Norheim O, Wikler D, editor. Inequalities in Health: concepts, measures and ethics. New York, NY: Oxford Univerity Press; 2013.

9. Sachs J. Macroeconomics and health: Investing in health for economic development. Report of the commission on macroeconomics and health. Geneva: World Health Organization; 2001.

10. Sen A. Mortality as an indicator of economic success and failure: UNICEF Innocenti Lecture. Florence; 1995.

11. Commission on the Social Determinants of Health. Closing the gap in a generation: health equity through action on the social determinants of health. Final report of the Commission on Social Determinants of Health. Geneva: World Health Organisation; 2008. 12. Fogel RW. The Fourth Great Awakening and the Future of Egalitarianism. Chicago: University of Chicago Press; 2000.

13. McKeown T. The role of medicine: dream, mirage or nemesis? London Nuffield Provincial Hospitals Trust; 1976.

14. Sen A. Inequality Reexamined. Oxford: Oxford University Press; 1992.

15. Karasek R, Theorell T. Healthy work: stress, productivity, and the reconstruction of working life. New York: Basic Books; 1990.

16. Sen A. Development as Freedom. Oxford: Oxford University Press; 1999.

17. Stern N, Dethier JJ, Rogers H. Growth and empowerment: making development happen. Cambridge,Mass MIT Press; 2004.

18. Marmot M. Health in an unequal world. The Lancet. 2006;368(9552):2081-94.

19. Marmot M. Fair society, healthy lives : the Marmot review ; strategic review of health inequalities in England post-2010: [S.I.] : The Marmot Review; 2010.

20. Kelly Y, Sacker A, Del BE, Francesconi M, Marmot M. What role for the home learning environment and parenting in reducing the socioeconomic gradient in child development? Findings from the Millennium Cohort Study. ArchDisChild. 2011;96(9):832-7.

21. Stuckler D, Basu S, Suhrcke M, Coutts A, McKee M. The public health effect of economic crises and alternative policy responses in Europe: an empirical analysis. Lancet. 2009;374(9686):315-23.

22. Lundberg O, Dahl E, Fritzell J, Palme J, Sjoberg O. Social protection Policies, income and health inequalities. GDP, taxes, income and welfare task group final report 2012 [ 23. Victora CG, Aquino EM, Leal MdC, Monteiro CA, Barros FC, Szwarcwald CL. Maternal and child health in Brazil: progress and challenges. Lancet. 2011;28(377):1863-76. 